\title{
RHINOLOGY
}

\section{Structural changes in the extracellular matrix after cross-linking of nasal polyp tissue}

\section{Cambiamenti strutturali della matrice extracellulare dopo cross-linking del tessuto polipoide nasale}

\author{
Nathalia Coronel ${ }^{1 *}$, Rogério Pezato ${ }^{1 *}$, Jônatas Bussador do Amaral ${ }^{1}$, Leandro Ticlia², Thiago Freire Pinto Bezerra ${ }^{3}$, \\ Lígia Ferreira Gomes², Juliana Dreyfuss ${ }^{4}$, Wallace Chamon, ${ }^{5,6}$, Luiz Carlos Gregório ${ }^{1}$ \\ ${ }^{1}$ ENT Research Laboratory, Department of Otolaryngology-Head and Neck Surgery, Federal University of Sao Paulo, Sao Paulo, \\ Brazil; ${ }^{2}$ Laboratory of Microrheology and Molecular Physiology, Institute of Physics, University of São Paulo-USP, São Paulo, SP, \\ Brazil; ${ }^{3}$ Department of Otolaryngology, Federal University of Pernambuco-UFPE, Recife, PE, Brazil; ${ }^{4}$ Department of Biochemistry, \\ Federal University of São Paulo-Unifesp, São Paulo, SP, Brazil; ${ }^{5}$ Department of Ophthalmology and Visual Sciences, Federal \\ University of São Paulo-Unifesp, São Paulo, SP, Brazil; ${ }^{6}$ Department of Ophthalmology and Visual Sciences, College of Medicine, \\ University of Illinois at Chicago, Chicago, IL, United States \\ ${ }^{*}$ N. Coroneland R. Pezato contributed equally to this work.
}

\begin{abstract}
SUMMARY
Chronic rhinosinusitis with nasal polyposis is a disease characterised by a mechanical dysfunction that facilitates anomalous growth of the nasal mucosa, due to its unique remodelling process. The development of procedures capable of interfering with this process is thus of the utmost importance. This study deals with the evaluation of the effects of cross-linking upon the nasal polyp tissue extracellular matrix. Six patients undergoing surgery for polypectomy were selected. The riboflavin/UVA collagen cross-linking technique was applied to the surface of epithelialised and de-epithelialised resected polyps of the intervention group. The control group polyps were not submitted to cross-linking procedures. Ultrathin polyp tissue sections $(8 \mu \mathrm{m})$ were processed for immunofluorescence with mouse anti-type I collagen antibody and AlexaFluor 488 conjugated secondary antibody plus DAPI counterstaining, and analysed by confocal microscopy. The effect of riboflavin/ UVA collagen cross-linking was visible on confocal fluorescence microscopy. Quantitative morphology was associated with fluorescence imaging analysis, and pixel density and brightness were evaluated. The surface of treated polyps exhibited a higher density of collagen fibres compared to control polyps, as could be observed both visually and through objective measurements of the fluorescent regions. The effect was enhanced on the surface of the de-epithelialised polyps. The higher density of collagen fibres exhibited by the deepithelialised treated polyps demonstrates the feasibility of this technique in interfering with the remodelling process and the mechanical dysfunction found in chronic rhinosinusitis with nasal polyposis.
\end{abstract}

KEY WORDS: paranasal sinus disease, chronic disease, rhinosinusitis, chronic rhinosinusitis, sinusitis

\section{RIASSUNTO}

La rinosinusite cronica con poliposi nasale è una malattia caratterizzata da una disfunzione meccanica che facilita la crescita anomala della mucosa nasale, a causa del suo peculiare processo di rimodellamento. Questo studio si propone di valutare gli effetti del cross-linking sulla matrice extracellulare del tessuto del polipo nasale. Sono stati selezionati sei pazienti sottoposti ad intervento chirurgico di polipectomia. È stata applicata la tecnica del cross linking del collagene con riboflavina / UVA alla superficie dei polipi resecati epitelizzati e disepitelizzati del gruppo di pazienti sottoposti ad intervento. I polipi del gruppo di controllo non sono stati sottoposti a procedure di cross linking. Le sezioni ultrasottili $(8 \mu \mathrm{m})$ di tessuto polipoide sono state analizzate mediante immunofluorescenza con anticorpi anti collagene di tipo I di topo e anticorpi secondari coniugati AlexaFluor 488 con controcolorazione DAPI e analizzate mediante microscopia confocale. L'effetto del cross-linking è risultato visibile al microscopio confocale a fluorescenza. La morfologia
Received: December 11, 2019

Accepted: August 4, 2020

\section{Correspondence}

Rogério Pezato

ENT Research Lab. Department of Otorhinolaryngology - Head and Neck Surgery, Federal University of Sao Paulo. Rua Pedro de Toledo 781, 1 o andar, sala 3 - Vila Clementino - São Paulo - SP - Brazil CEP 04039-032

Tel. +55 11 5576-4848 PABX number:17267

E-mail: pezatobau@gmail.com

\section{Funding}

This work was supported by Coordenação de Aperfeiçoamento de Pessoal de Nível Superior (CAPES) PROAP

\section{Conflict of interest}

The Authors declare no conflict of interest.

How to cite this article: Coronel N, Pezato R, do Amaral JB, et al. Structural changes in the extracellular matrix after cross-linking of nasal polyp tissue. Acta Otorhinolaryngol Ital 2020;40:426434. https://doi.org/10.14639/0392-100X-N0566

(c) Società Italiana di Otorinolaringoiatria e Chirurgia Cervico-Facciale

\section{ल)(1)}

This is an open access article distributed in accordance with the CC-BY-NC-ND (Creative Commons Attribution-NonCommercial-NoDerivatives 4.0 International) license. The article can be used by giving appropriate credit and mentioning the license, but only for non-commercial purposes and only in the original version. For further information: https:// creativecommons.org/licenses/by-nc-nd/4.0/deed.en 
quantitativa è stata associata all'analisi di imaging in fluorescenza e sono state valutate la densità e la luminosità dei pixel. La superficie dei polipi trattati mostrava una maggiore densità di fibre di collagene rispetto ai polipi di controllo, come è stato possibile osservare sia visivamente che attraverso misurazioni oggettive delle regioni fluorescenti. L'effetto è stato potenziato sulla superficie dei polipi disepitelizzati. La maggiore densità di fibre di collagene esibita dai polipi trattati disepitelizzati dimostra la fattibilità di questa tecnica per interferire con il processo di rimodellamento e affrontare la disfunzione meccanica riscontrata nella rinosinusite cronica con poliposi nasale.

PAROLE CHIAVE: malattia dei seni paranasali, patologia cronica, rinosinusite, rinosinusite cronica, sinusite

\section{Introduction}

Chronic rhinosinusitis with nasal polyposis (CRSwNP) is characterised by chronic inflammation of the nasal mucosa with an altered remodelling process, which affects extracellular matrix $(\mathrm{ECM})$ formation and facilitates mechanical dysfunction and oedema formation ${ }^{1}$.

The pathogenesis of CRSwNP is still not fully understood ${ }^{2,3}$; however, its foundation is the aforementioned chronic inflammatory process, characterised by a major imbalance in immunomodulation which increases inflammatory cells (such as dendritic cells, eosinophils, and T helper cells) and decreases immunoregulatory cells (such as regulatory $\mathrm{T}$ cells), as well as an impaired immunomodulation of mesenchymal stem cells ${ }^{4,5}$.

Studies on the mechanical forces involved in nasal polyp development have been conducted in an attempt to at least partly elucidate the pathophysiology of CRSwNP ${ }^{1,6,7}$. Changes in the mechanical response of the nasal mucosa have been observed in patients with CRSwNP compared to the healthy mucosa of the middle meatus, with a loss of effectiveness in adequately increasing the interstitial hydrostatic pressure (IHP) in response to water inflow during the inflammatory process ${ }^{1}$.

This discovery provides a new perspective for biomechanical management of CRSwNP ${ }^{1}$ beyond treatment of the inflammatory process (corticosteroids, non-steroidal anti-inflammatory drugs, leukotriene receptor antagonists, anti-immunoglobulin antibodies and biological agents that modulate the inflammatory environment) ${ }^{8}$.

Within this context, the study of the mechanical dysfunction of CRSwNP has become increasingly relevant. It has previously been shown that ECM composition interferes with the biomechanical response of nasal mucosa. Nasal mucosa with fibrosis (synechiae) and healthy nasal middle meatus mucosa produce similar mechanical responses, suggesting that changes in ECM composition may contribute to prevent oedema formation and, potentially, have an impact on CRSwNP treatment ${ }^{7}$.

Recent studies have confirmed that increased IHP contributes to a reduction of nasal polyps. In one investigation, the authors increased this pressure by imparting continuous positive airway pressure (CPAP) in nasal polyp tissue. Such indirectly increased interstitial hydrostatic pressure was associated with a decrease in polyp volume and milder nasal-obstruction symptoms ${ }^{9}$. Considering the close interdependence between the IHP response and ECM composition, the remodelling process is an essential target in approaching the mechanical dysfunction of CRSwNP.

It is reasonable to speculate that not only would changes in ECM composition be capable of altering the mechanical properties of the tissue, but also that structural changes in the existing ECM could affect tissue mechanical properties. In ophthalmology, the riboflavin/UVA cross-linking technique has been used to alter ECM conformation and thus prevent the progression of corneal bulging in keratoconus, a disease characterised by derangement of ECM deposition, which facilitates change in the shape of the cornea ${ }^{10-12}$. In the same way, the strengthening of the structures that compose the ECM in nasal polyp mucosa might impact the remodelling process and act on the biophysics mechanisms involved in the nasal polyp development ${ }^{13}$.

In this context, we evaluated the effect of this cross-linking technique upon polyp stromal collagen in patients with CRSwNP.

\section{Materials and methods}

This study was approved by the University of São Paulo Research Ethics Committee, protocol number 2905802, and conducted in accordance with the provisions of the Helsinki Declaration.

Histological sections of nasal polyp tissue from 6 patients with NP, diagnosed according to the European Position Paper on Rhinosinusitis and Nasal Polyps (EPOS) criteria, were evaluated ${ }^{8}$. Patients between 18 and 60 years of age, non-steroidal anti-inflammatory tolerant, non-smokers were selected. The exclusion criteria were degenerative or autoimmune diseases, cystic fibrosis, pregnancy and topical or systemic corticosteroid therapy within the 4 weeks preceding surgery for removal of nasal polyps.

\section{Application of the cross-linking technique}

Immediately after resection, polyp fragments were prepared and divided into two groups: control and intervention. The control group received no intervention. In the intervention group, riboflavin/UVA cross-linking was performed on the epithelial surface of the polyps of patients 1, 2, 3, 4 and 5 . 
In patient 6, the polyp was cut in half and the treatment applied to the de-epithelialised cut surface (Fig. 1).

In the intervention group, a photosensitising solution containing $0.1 \%$ riboflavin-5-phosphate and $20 \%$ dextran T-500 was applied to the surface of the polyp every 5 minutes for 30 minutes to ensure saturation of the polyp stroma with riboflavin. After 30 minutes, UVA radiation $(365 \mathrm{~nm})$ was applied $45 \mathrm{~mm}$ from the polyp surface, for 30 minutes, using a solid-state device (X-Link, Opto Eletrônica, São Carlos, Brazil) with a surface irradiance output of $3 \mathrm{~mW} /$ $\mathrm{cm}^{2}$ (Fig. 1). The energy applied was $5.375 \mathrm{~J} / \mathrm{cm}^{2}$. Surface irradiation was ensured by continuous, microprocessorbased, automated monitoring by the X-Link device, which uses an internal power meter. After application of the crosslinking technique, polyps were frozen at $-80^{\circ} \mathrm{C}$.

Ultrathin cryostat sections $\left(8 \mu \mathrm{m},-21^{\circ} \mathrm{C}\right)$ of treated and untreated polyps were obtained and analysed.

In the first four patients, sections were made parallel to the surface exposed to riboflavin/UVA. In patients 5 and 6 , sec-

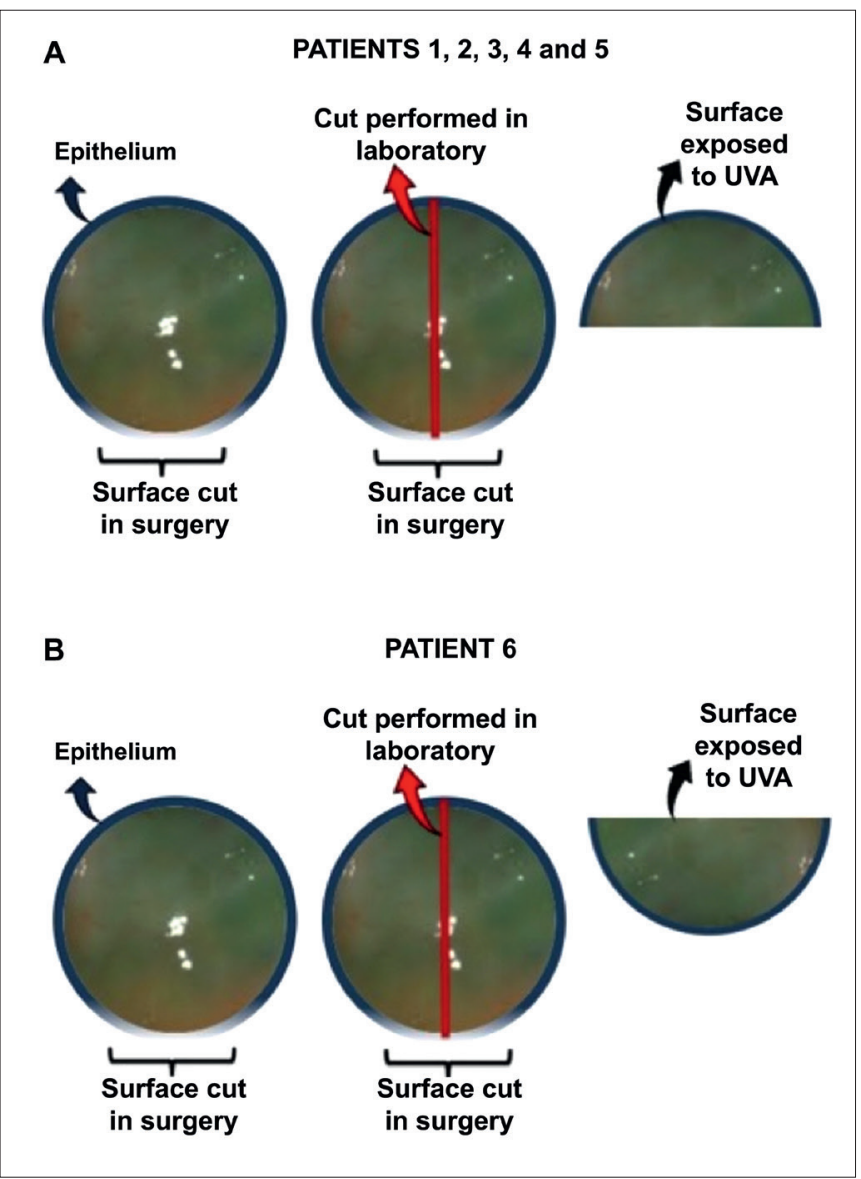

Figure 1. Polyp and area of riboflavin/UVA application. (A) In patients 1, 2, 3, 4, and 5: on the epithelialised surface of the polyp. (B) In patient 6: polyp cut in half and treatment applied on the de-epithelialised cut surface. tions were obtained longitudinally (perpendicular to the exposed surface), so that all slides included the UVA-exposed area and the underlying stroma.

\section{Eosinophil count}

Part of the polyps was fixed using $10 \%$ acetaldehyde, maintained for 24 hours at room temperature, and then preserved in $70 \%$ alcohol for analysis. The previously fixed nasal tissue portions were embedded in paraffin and $4-\mu \mathrm{m}$-thick sections were obtained using a microtome. All sections were affixed onto Superfrost Plus glass slides (Menzel Glaser, Braunschweig, Germany) and dried at $60^{\circ} \mathrm{C}$ for a few hours. For deparaffinisation, slides were washed successively in xylene ( 3 times for 10 minutes), $100 \%$ ethanol ( 2 times for 5 minutes), $90 \%$ ethanol (2 times for 5 minutes) and $70 \%$ ethanol ( 2 times for 5 minutes). The nuclei were stained with alum haematoxylin (Lillie-Mayer's solution) for 5 minutes and rinsed in running tap water. Differentiation was performed with $0.3 \%$ acid alcohol, sections were rinsed again in running tap water and, subsequently, in Scott's tap water substitute (sodium hydrogen carbonate $10 \mathrm{~g}$, magnesium sulphate $100 \mathrm{~g}$, distilled water $5 \mathrm{~L}$ ).

After rinsing in tap water, sections were stained with eosin solution ( $1 \%$ eosin Y $400 \mathrm{~mL}, 1 \%$ aqueous phloxine $40 \mathrm{~mL}$, $95 \%$ alcohol $3100 \mathrm{~mL}$ and glacial acetic acid $16 \mathrm{~mL}$ ) for 2 minutes, dehydrated, and cleared.

Histological examination was performed by a pathology expert through a Leica DM2000 binocular microscope at 400x magnification. The absolute number of eosinophils per high-power field (HPF) was counted in an average of 10 independent fields of view selected from the most inflamed area of tissue.

\section{Processing for immunofluorescence}

The slides were washed with phosphate-buffered saline (PBS), covered with $2.5 \%$ PBS and albumin solution, and stored in a moisture chamber under refrigeration. After 2 hours, they were incubated with primary antibody (antitype I collagen, Calbicochem, Darmstadt, Germany) at 1:50 concentration in PBS containing $1 \%$ bovine serum albumin and $0.1 \%$ saponin.

The next day, the slides were again rinsed with PBS and incubated with secondary antibody (AlexaFluor 488 conjugated anti-mouse IgG, Molecular Probes, Carlsbad, CA) at 1:300 concentration for 30 minutes. Next, slides were washed with ice-cold PBS and incubated with 1:2500 DAPI (4,6-diamidino-2-phenylindole dihydrochloride, Molecular Probes) in a PBS solution containing $0.1 \%$ saponin, for 30 minutes, to ensure nuclear staining. Finally, slides were washed again with PBS and mounted with FluoromountG liquid medium (Electron Microscopy Sciences, Hatfield, 
PA) and, after 12 hours, were sealed with clear nail polish and stored at $-80^{\circ} \mathrm{C}$.

For each patient, one intervention slide and one control slide were set aside for use as negative controls. These slides were not treated with primary antibodies, for purposes of comparison with control-group polyps.

All slides were visualised and photographed using a Leica TCS SP8 confocal laser scanning microscope.

\section{Comparison of images after tissue immunofluorescence}

Images of sections of epithelialised and non-epithelialised polyps were first compared visually, with analysis focusing on the surface region to which riboflavin/UVA was applied and the corresponding region on the control polyp. Collagen fibres were stained green, while the nuclei of the epithelial cells were stained blue.

\section{Objective assessment of images}

The images obtained by confocal microscopy were also examined for two objective parameters: tissue texture, through pixel encoding by the local binary pattern (LBP) method and luminous intensity distribution.

1. Analysis of tissue texture by pixel encoding

LBP is a method used in the field of computer vision for texture analysis of monochrome digital images. In the context of a digital image, the texture of each pixel is defined by the local variations in intensity of the nearest neighbouring pixels. When applied to an image, LBP compares the intensities of a central pixel with those of its 8 neighboring pixels, assigning a value of 1 when the intensity of a neighboring pixel is greater than or equal to the intensity of the central pixel and 0 otherwise. This generates a numeric representation that consists of a sequence of 8 binary digits ( 0 or 1 ), which represents the characteristics of the central pixel. This sequence of 8 binary digits is then expressed as its decimal equivalent. The 8-digit binary sequence can generate up to 256 different local patterns, some of which can be considered equivalent because they represent the same texture pattern.

All binary sequences representing the same texture were grouped into the same set, known as the LBP code set. From this perspective, up to 10 sets of LBP codes could be created, which were denoted by numbers 0 to 9 . Each of these codes was associated with a specific image feature. For example, codes 2 and 6 were associated with half-edges, while codes 3 and 5 were associated with dark and light edges, respectively. Half-edges, corresponding to discontinuous edges which do not exceed 2 pixels in length, represent collagen fibres that were photographed only partly or present any loss of continu- ity. Edges, in our context, represent the contour of whole collagen fibres.

We applied the LBP method only to the regions of interest of the confocal photomicrographs. Data were obtained in the area juxtaposed to the surface to which the cross-linking agents were applied, at a depth of $105 \mu \mathrm{m}$ (Figs. 2A-C), and in the control polyps, in the corresponding area also $105 \mu \mathrm{m}$ in depth (Figs. 2D-F). Finally, a histogram of the decimal values attributed to each pixel group was generated, representing the texture pattern associated to the digital images of clinical specimens.

2. Analysis of luminous intensity distribution Analysis of luminous intensity distribution specifically evaluates pixels associated with greater brightness. In our photomicrographs, brighter areas (i.e., those with greater luminosity) represent collagen fibres.

Brightness values in a monochrome image range from 0 to 255 , where 0 represents the darkest hue and 255 , the lightest. Bright pixels were defined as those with a hue exceeding a given threshold $\mathrm{T}$, where $0 \leq \mathrm{T} \leq 255$. One threshold value was attributed to the whole set of digital images under study. Subsequently, it was calculated which percentage of the whole image pixels belong to the bright part of the image, revealing the extension of the image area occupied by collagen fibres. This strategy allowed collagen fibre areas of control and intervention images to be compared, as the control and intervention images were acquired under the same conditions.

\section{Results}

\section{Eosinophils per High-Power Field (HPF)}

All 6 polyps analysed presented more than 5 eosinophils per HPF, characterising the eosinophilic endotype of CRSwNP.

\section{Tissue immunofluorescence microscopy}

Microscopically, a $105 \mu \mathrm{m}$-thick fluorescent line was visible on the treated surface of epithelialised (Figs. 3A-B) and de-epithelialised (Figs. 3C-D) polyps, stratified into a superficial zone with more organised collagen fibres and a deeper zone with less organised collagen fibres. The differences between the control and intervention groups, concerning the organisation of collagen fibres were even more evident in the de-epithelialised polyps.

\section{Analysis of tissue texture by pixel encoding}

Among the controls of the epithelialised polyp group, the most frequent LBP profile observed was code 4 (Fig. 4A), corresponding to the edges of collagen fibres. Edge detection occurred due to the contrast of the bright collagen fi- 

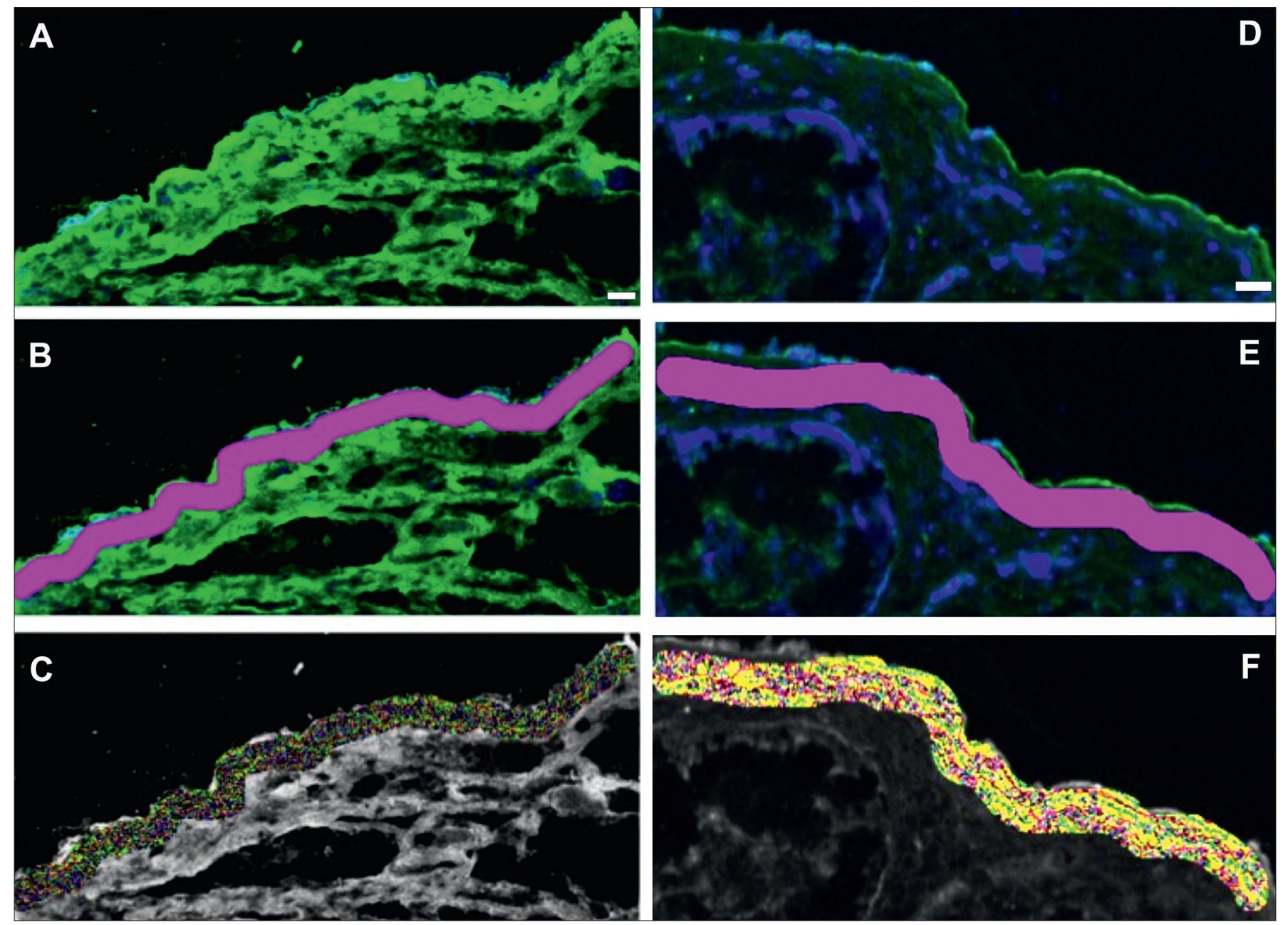

Figure 2. Area of LBP analysis in a representative treated polyp (patient 6). (A) Histological section to which cross-linking was applied. (B) In pink, demarcated area at a depth of $105 \mu \mathrm{m}$ from which LPB codes were obtained. (C) Colour representation of LBP codes in the previously demarcated area. Area of LBP analysis in a representative control polyp (patient 6). (D) Histological section of the polyp. (E) In pink, demarcated area at a depth of $105 \mu \mathrm{m}$ from which LPB codes were obtained. (F) Colour representation of LBP codes in the previously demarcated area.

bres with dark areas in which fibres were absent. The presence of edges implied a reference level for the control fibre densities in the epithelialised polyp tissues. The exposure of the epithelialised polyp tissues to riboflavin/UVA induced a distinct LBP profile. The lowering of code 4 relative frequencies and the higher frequencies for code 8 corresponded to the bright hue of the labeled areas, denoting a greater concentration of collagen fibres in which individual edges were less observable.

Among the de-epithelialised polyps (Fig. 4B), code 4 was also the most frequent LBP profile among the control polyps, while the UVA-exposed de-epithelialised polyp had its highest peak on code 9 .

The tissue texture analysis demonstrated that both the epithelialised and the de-epithelialised polyps increased collagen fibre concentration.
In both situations, the pattern of distribution of LBP code densities after UVA exposure has changed; density of code 4 decreased in the treated polyps, which corresponds to an increase in collagen fibre concentration.

\section{Luminous intensity distribution}

Figure 5 shows a plot of tissue luminous intensity distribution for individual patients. It was demonstrated a higher luminous intensity after UVA applications, which corresponds to greater collagen fibre densities in the analysed areas.

\section{Discussion}

Studies of tissue biomechanics in NP have led to a progressive paradigm shift by revealing that the development of 

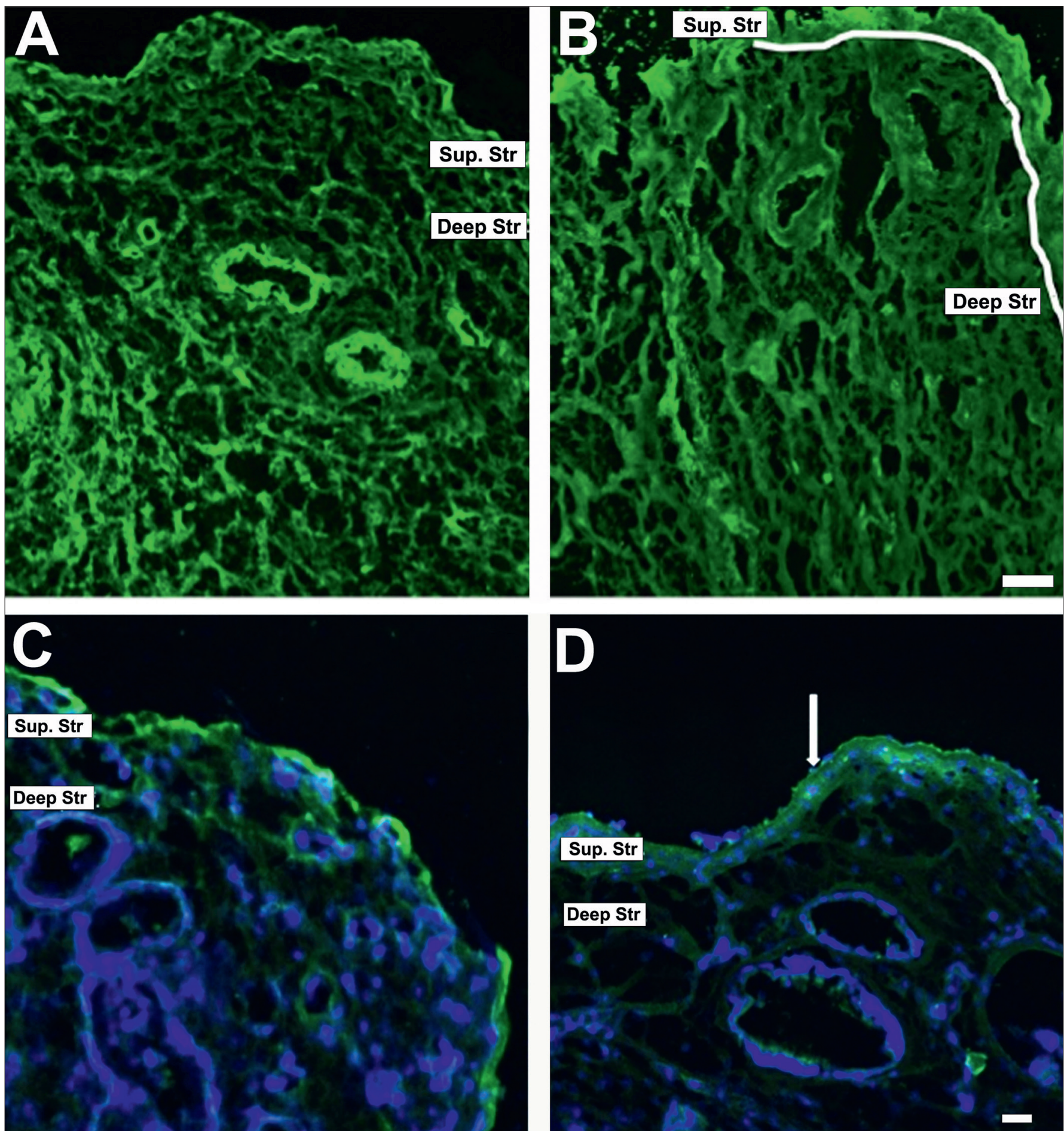

Figure 3. Photomicrograph of epithelialised nasal polyp section stained with anti-type I collagen antibody. (A) Control polyp, with rather disorganised collagen fibres (green) on the cut surface. (B) Intervention polyp exposed to riboflavin/UVA cross-linking of the epithelialised surface, with greater organisation of collagen fibres in the superficial stroma (above and to the right of the white line). Photomicrograph of de-epithelialised nasal polyp section stained with anti-type I collagen antibody. (C) Control polyp, with rather disorganised collagen fibres (green) on the cut surface. (D) Intervention polyp exposed to riboflavin/UVA cross-linking of the de-epithelialised surface, with highly organised collagen fibres in the superficial stroma (arrow). Sup. Str.: superficial stroma; Deep Str.: deep stroma. 


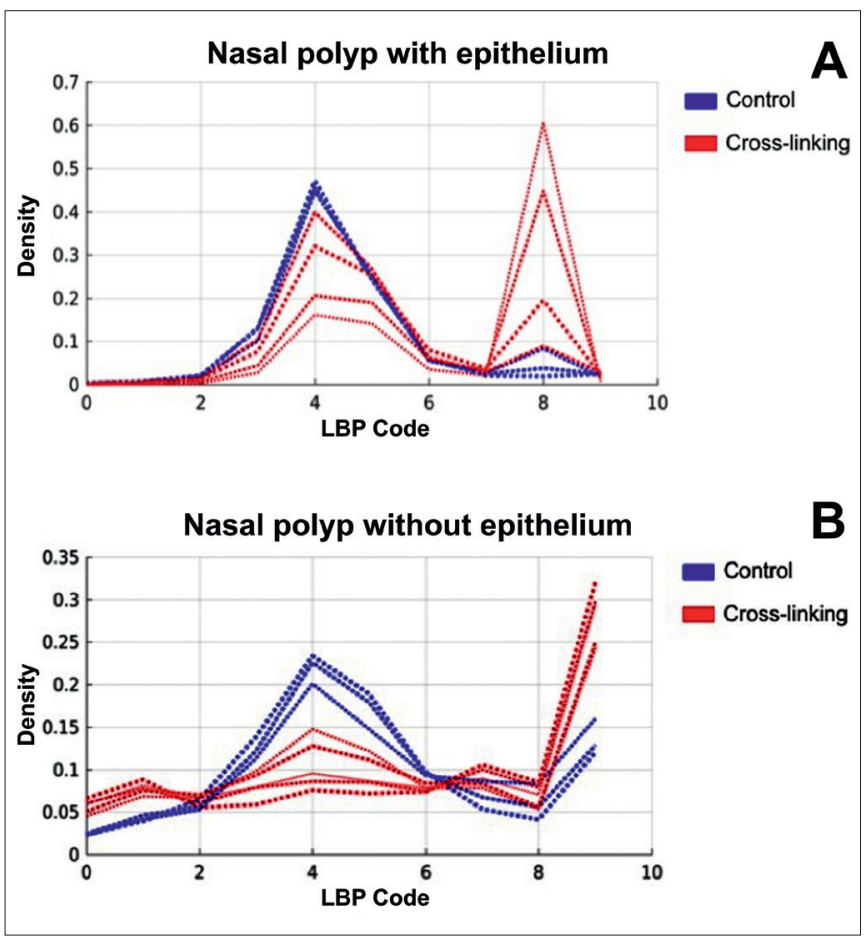

Figure 4. Histogram of LBP code density in epithelialised polyp tissue. In the control polyp, the peak (blue) occurs on LBP code 4, which represents greater presence of pixels corresponding to edges. In the polyp exposed to cross-linking, the peak occurs on code 8, which represents uniform greencoloured regions, corresponding to immunostained collagen fibres (A). Histogram of LBP code density in de-epithelialised polyp tissue. In the control polyp, the sole peak occurs on code 4 , which represents a greater presence of edge-associated pixels, whereas in the polyp exposed to cross-linking, the peak occurs on code 9 (B).

this condition is based on two processes: not only chronic inflammation, but also mechanical dysfunction. Within this context, the present study aimed to induce changes in the structure of the polyp ECM with a view to potentially modify the mechanical dysfunction found in polyp tissue. This was the first investigation to evaluate a method capable of altering the shape and density of collagen in the ECM of nasal polyps. For this purpose, we used the riboflavin/UVA collagen cross-linking process. This method was chosen because it is already in clinical use in ophthalmology and has proven efficient in modifying the natural history of keratoconus, a disease characterised by derangement of ECM deposition, which facilitates change in the shape of the cornea ${ }^{10-12,14}$.

In CRSwNP, the composition of the ECM is different from that of normal nasal tissue, especially regarding collagen, which is present at lower concentrations ${ }^{15}$. This process of altered tissue remodelling in NP has direct effects on the biomechanical properties of the polypoid tissue, facilitating tissue growth and oedema ${ }^{1}$.
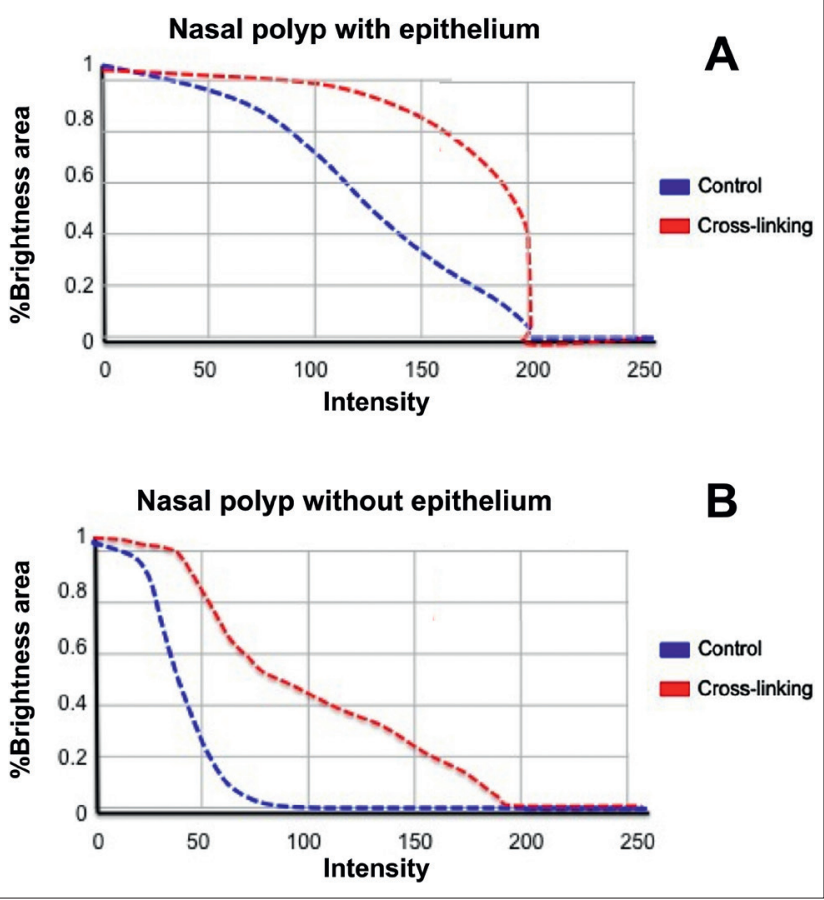

Figure 5. Mean luminous intensity curves of epithelialised (A) and de-epithelialised polyps (B). Blue represents control sections, and red, the intervention (treated) sections.

At the cellular level, ontological genetic analysis has shown that, in mesenchymal stem cells derived from nasal polyps, genes related to the ECM remodelling process are differentially modulated when compared to those of bone marrowderived mesenchymal stem cells ${ }^{5}$.

It has also been demonstrated that fibrotic tissue found in the nasal mucosa (synechiae) and the mucosa of the middle nasal meatus have similar mechanical properties. Moreover, it is suggested that the fibrotic modification of the biomechanical properties of the nasal mucosa of patients with CRSwNP, a tissue repair phenomenon in which increased collagen concentrations play a predominant role, could interfere in the altered remodelling process found in polypoid tissue ${ }^{7}$.

Collagen fibres provide tensile strength to tissues. In living tissue, these fibres are stabilised through the formation of intermolecular covalent bonds, mediated by lysyl oxidase enzymes ${ }^{16}$. The intensity of this stabilisation can be increased artificially by application of UVA radiation directly to tissue, without altering the composition of the underlying ECM, through the cross-linking technique ${ }^{12}$.

Previous studies performed on the porcine cornea have shown that riboflavin acts as a photosensitising agent and, when irradiated by UVA, leads to the formation of free radicals that create new chemical bonds within the corneal 
stroma. This procedure increases the diameter of the collagen fibres and establishes stronger interfibrillar attachment, increasing the biomechanical stability of the exposed tissue ${ }^{10-12,17}$.

Based on this method, we employed the same protocol for riboflavin/UVA exposure used in ophthalmology for keratoconus treatment in order to evaluate whether the same changes that occur in the corneal ECM can be induced in nasal polyp tissue ${ }^{18}$.

In the images obtained from the epithelialised polyp, there was a slight increase in fibre density up to $105 \mu \mathrm{m}$ below the epithelium, i.e., the depth reached by UVA radiation. Increased fibre density data were corroborated by objective analysis of the pixel patterns and brightness of images.

The increase in collagen fibre density was greater in the de-epithelialised polyp, with a higher fibre density at the surface where the riboflavin and UVA were applied. This revealed that the presence of the epithelium interfered negatively with riboflavin penetration into the stroma. This phenomenon resembles that found in the cornea, where removal of the epithelium intensifies the effect of crosslinking ${ }^{17,18}$.

Objective analysis of pixel patterns and luminosity in the irradiated region reinforces the results of visual examination and provides reliable data for comparison, showing a greater impact on fibre density in the treated polypoid tissue than in untreated tissue.

These results also provide an opportunity for further investigations to replicate this pilot experiment, prompting further research into the ECM of the nasal polyp stroma and on the potential impact of structural changes to the conformation of the constituent proteins of the ECM on the mechanical properties of nasal polypoid tissue.

If the tissue changes observed after exposure to the crosslinking technique are shown to have a direct effect on the biomechanics of nasal polypoid tissue, this would open new avenues for the treatment of nasal polyposis, no longer based on anti-inflammatory agents or surgery alone, but rather by directly altering the mechanical properties of the affected tissue.

This technique has the potential for immediate application after polypectomy in patients with a history of recurrent CRSwNP, when this mucosa is already partially de-epithelialised. Once polyps have been removed and mucosal re-epithelialisation has not yet begun, one would expect for cross-linking to have the same effect observed in the de-epithelialised polyp in this study. We could also take advantage of the amplification of access to sinus cavities after sinus surgery and promote cross-linking on sinus walls.

Within this context, riboflavin/UVA cross-linking might also have utility as an outpatient office procedure to slow the growth of polypoid tissue, as our study showed that, although the method was less effective in epithelialised tissue, it still had an effect on the extracellular matrix structure of the nasal polyp. Prospective clinical studies are needed to evaluate the applicability of this procedure in the treatment of CRSwNP.

\section{Conclusions}

The results of this study show that riboflavin/UVA crosslinking promotes changes in the structural conformation of collagen fibres and increases their density on the exposed surface of nasal polyp tissue.

\section{References}

1 Pezato R, Voegels R, Pinto Bezerra T, et al. Mechanical dysfunction in the mucosal oedema formation of patients with nasal polyps. Rhinology 2014;52:162-6. https://doi.org/10.4193/Rhin13.066

2 Gelardi M, Piccininni K, Quaranta N, et al. Olfactory dysfunction in patients with chronic rhinosinusitis with nasal polyps is associated with clinical-cytological grading severity. Acta Otorhinolaryngol Ital 2019;39:329-35. https://doi.org/10.14639/0392-100X-2426

3 Pistochini A, Rossi F, Gallo S, et al. Multiple gene expression profiling suggests epithelial dysfunction in polypoid chronic rhinosinusitis. Acta Otorhinolaryngol Ital 2019;39:169-77. https://doi. org/10.14639/0392-100X-2361

4 Pezato R, Pérez-Novo CA, Holtappels G, et al. The expression of dendritic cell subsets in severe chronic rhinosinusitis with nasal polyps is altered. Immunobiology 2014;219:729-36. https://doi.org/10.1016/j. imbio.2014.05.004

5 Oliveira PWB, Pezato R, Agudelo JSH, et al. Nasal polyp-derived mesenchymal stromal cells exhibit lack of immune-associated molecules and high levels of stem/progenitor cells markers. Front Immunol 2017;8:39. https://doi.org/10.3389/fimmu.2017.00039

6 do Amaral JB, Bloise AC, França CN, et al. Alterations in cellular force parameters and cell projections in nasal polyps-derived fibroblasts. Auris Nasus Larynx 2020;47:98-104. https://doi.org/10.1016/j. anl.2019.06.007

7 Gregório L, Pezato R, Felici RS, et al. Fibrotic tissue and middle turbinate exhibit similar mechanical properties. is fibrosis a solution in nasal polyposis? Int Arch Otorhinolaryngol 2017;21:122-5. https:// doi.org/10.1055/s-0036-1593728

8 Fokkens WJ, Lund VJ, Hopkins C, et al. European Position Paper on rhinosinusitis and nasal polyps 2020. Rhinology 2020;58(Suppl S29):1-464.

9 Balsalobre L, Pezato R, Mangussi-Gomes J, et al. What is the impact of positive airway pressure in nasal polyposis? An experimental study. Int Arch Otorhinolaryngol 2019;23:147-51. https://doi. org/10.1055/s-0038-1676095

10 Spoerl E, Huhle M, Seiler T. Induction of cross-links in corneal tissue. Exp Eye Res 1998;66:97-103. https://doi.org/10.1006/exer.1997.0410

11 Wollensak G, Spoerl E, Seiler T. Riboflavin/ultraviolet-a-induced collagen crosslinking for the treatment of keratoconus. Am J Ophthalmol 2003;135:620-7. https://doi.org/10.1016/S0002-9394(02)02220-1

12 Wollensak G, Spoerl E, Seiler T. Stress-strain measurements of human and porcine corneas after riboflavin-ultraviolet-A-induced cross-linking. J Cataract Refract Surg 2003;29:1780-5. https://doi. org/10.1016/S0886-3350(03)00407-3 
13 Pezato R, Voegels RL, Pignatari S, et al. Nasal polyposis: more than a chronic inflammatory disorder - a disease of mechanical dysfunction - the São Paulo position. Int Arch Otorhinolaryngol 2019;23:2419. https://doi.org/10.1055/s-0038-1676659

14 Daxer A, Fratzl P. Collagen fibril orientation in the human corneal stroma and its implication in keratoconus. Invest Ophthalmol Vis Sci 1997;38:121-9.

15 Van Bruaene N, Derycke L, Perez-Novo CA, et al. TGF- $\beta$ signaling and collagen deposition in chronic rhinosinusitis. J Allergy Clin Immunol 2009;124:253-9, 259.e1-2. https://doi.org/10.1016/j.jaci.2009.04.013
16 Kagan HM, Li W. Lysyl oxidase: properties, specificity, and biological roles inside and outside of the cell. J Cell Biochem 2003;88:66072. https://doi.org/10.1002/jcb.10413

17 Wollensak G, Wilsch M, Spoerl E, et al. Collagen fiber diameter in the rabbit cornea after collagen crosslinking by riboflavin/uva. Cornea 2004;23:503-7. https://doi.org/10.1097/01.ico.0000105827.85025.7f

18 Bottós KM, Regatieri CVS, Dreyfuss JL, et al. Immunofluorescence confocal microscopy of porcine corneas following collagen crosslinking treatment with riboflavin and ultraviolet A. J Refract Surg 2008;24:S715-S9. https://doi.org/10.3928/1081597x-20080901-14 